\title{
La función de filiación en instituciones de alojamiento. Un análisis mediante ceremonias mínimas. ${ }^{1}$
}

\section{The filiation function in housing institutions. An analysis through minimal ceremonies.}

\author{
Rosario Telleria ${ }^{2}$
}

\section{Resumen}

El presente artículo está basado en la práctica del Acompañante Convivencial de una Institución de Alojamiento para Niñas y Adolescentes en la ciudad de Rosario, dependiente de organismo del Poder Ejecutivo del estado provincial en co-gestión con una asociación civil de la mencionada ciudad.

Para analizar las posiciones en el lazo de los adultos y de las niñas y adolescentes de la institución y concluir en la producción de lazos filiatorios entre ellos, se caracterizan tres enlaces discursivos de la función institucional de filiación; entendiendo al lazo filiatorio como un lazo paradojal que liga y desliga a la vez.

Los enlaces discursivos de la función institucional de filiación son: la relación asimétrica entre los adultos y las niñas y adolescentes, la empatía y el miramiento, y la transmisión de límites. Estos enlaces se despliegan en el devenir cotidiano-convivencial de la institución y son analizados mediante ceremonias mínimas.

Palabras claves: función institucional de filiación - relación asimétrica - empatía y miramiento - transmisión de límites - ceremonias mínimas

\section{Abstract}

This article is based on the practice of the Cohabitation Accompanist at a Housing Institution for Girls and Adolescents in the city of Rosario under the executive branch of the provincial state in co-management with a civil association.

To analyze the relationship of the adults, girls, adolescents of the institution and to conclude in the production of filiatorial ties among them, we will caractherize three discursive links of the institutional filiation function, understanding the filial tie as a paradoxical one which binds and separates at the same time.

The discursive links of the institutional function of filiation are: the asymmetric relationship between adults, girls and adolescents, empathy and consideration, and the transmission of limits. These links are deployed in the everyday-coexistence in the institution and are beeing analyzed through minimal ceremonies.

Keywords: institutional function of filiation asymmetric relationship - empathy and observation - transmission of limits - minimum ceremonies

\footnotetext{
${ }^{1}$ El presente artículo fue reescrito sobre la base del Trabajo Integrador Final, homónimo, de la Carrera de Especialización en Psicología Clínica, Institucional y Comunitaria, del que soy autora. El trabajo, finalizado en 2017, fue dirigido por la Dra. Silvia Lampugnani

${ }^{2}$ Psicóloga. Especialista en Psicología Clínica, Institucional y Comunitaria.
} 


\section{Introducción}

El Sistema de Protección Integral de los Derechos de la Niñez y Adolescencia de la Provincia de Santa Fe, mediante la Ley 12.967 de Promoción y Protección Integral de los Derechos de las Niñas, Niños y Adolescentes, establece un marco legal que busca regular las separaciones de las niñas, niños y adolescentes de sus medios familiares por falta de cuidados y sostén en el crecimiento de ellos. Ante esta situación, y por el más breve lapso posible, puede recurrirse a una forma convivencial alternativa a la de su grupo familiar.

Esa posible alternativa nos obliga a repensar los modos de alojar en instituciones a niñas, niños y adolescentes cuyos padres no pudieron ser soportes de su crianza (Lampugnani, 2014) ¿Puede una institución de alojamiento producir lazos filiatorios? ¿Cómo es que esa producción puede llevarse adelante?

Sostenemos que es la figura de un adulto, sean o no sean los padres, que como tal asume una posición determinada en el lazo con el otro quien, mediante el sostén cotidiano-convivencial y el acompañamiento en el crecimiento del niño, niña y adolescente, puede instituir la función de filiación. Es resaltando esa posibilidad que la problemática de la crianza cobra un valor fundamental en la vida de estos sujetos y es desde ahí que intentamos hacer este desarrollo.

En el armado de este artículo nos encontramos con varias lecturas psicoanalíticas que, a nuestro entender, formulan una reducción de las funciones remitidas a figuras generando obstáculo para pensar las funciones institucionales de filiación más allá de la madre o el padre. De esta manera, se achica el campo para pensar las posibilidades del lazo filiatorio. Consideramos que las funciones que pueden dar lugar a que la compleja mecánica de la filiación se ponga en juego son aquellas que pueden soportar la alteridad con el otro, sea o no la madre o el padre.

Pensar al lazo filiatorio como estructuralmente paradojal (Kreszes, 20015), permite resaltar la responsabilidad del sujeto ante el acoplamiento totalizador fundante para el cachorro humano. Siguiendo los desarrollos de David Kreszes en la obra Superyó y Filiación:

Llamamos lazo filiatorio a una de las diversas modalidades de lo que situaremos como una relación de no relación con la alteridad (...) Continuidad y discontinuidad, ligadura y desligadura, participan de la estofa de la relación paterno-filial. No podremos referirnos al lazo en su vertiente de ligadura si al mismo tiempo no hablamos de su vertiente de desligadura. Nos oponemos a concebir al lazo filiatorio en tiempos de una cronología lineal -primero un tiempo de ligadura, después un tiempo de desligadura-, en tanto la estructura misma del lazo impone la ligadura y la desligadura. (Keszes, 2005:14)

No hay una relación causal entre el Otro y el sujeto, sino un acto de lectura que pone en juego la responsabilidad subjetiva. Como si las huellas del Otro se mantuvieran virtuales hasta que aparece la lectura de éstas; esta lectura, llamada acto psíquico da como emergente a un sujeto, el sujeto es ese acto de lectura de las huellas del Otro. Así, no puede pensarse al sujeto como una reacción, sino como una respuesta de las marcas del lazo filiatorio, lazo que liga y desliga a la vez. Al decir de Kreszes, "El sujeto no adviene sino en respuesta al llamado del Otro. Y en la respuesta misma lo encontramos tomando posición respecto a lo que llamamos la estofa paradojal del lazo". (Kreszes, 2005:14). La función institucional de filiación puede pensarse, entonces, como este acto de instituir sujeto en un lazo paradojal. 
Instituido el sujeto, quedan instituidas, también, las prohibiciones universales edípicas: incesto y parricidio. Si hay sujeto es porque no hay incesto ni parricidio, pensándolos como dos modos de eliminación de la alteridad: el incesto, al hacerse Uno con el Otro y el parricidio al desentenderse de las marcas del Otro.

Podemos caracterizar tres modos de relación de no relación con la alteridad (Kreszes, 2005) que dan lugar a la función institucional de filiación, o sea, que dan lugar a la emergencia del sujeto: el sostén de una relación asimétrica, la transmisión de límites y la empatía y miramiento ante el otro. Los tres enlaces discursivos nos hablan de una posición en el lazo con el otro. La demarcación de cada uno de ellos por separado se realiza a los fines de desmenuzar el análisis sobre las posiciones en el lazo, ya que los tres están intrínsecamente enlazados entre sí.

Esto quiere decir que si hay alguien que puede asumirse en una relación asimétrica con otro, o sea, puede asumirse en un lugar distinto, es porque sostiene una empatía y miramiento que indica la lectura del otro como alguien diferente a uno. Además, la diferencia de lugares implica la diferencia de funciones. El Otro como auxiliar en el crecimiento del cachorro humano tiene la función de enlazar al sujeto esperando su respuesta. Es fundamental para sostener la diferencia entre Uno y Otro mantener una actitud tierna, entendiendo a ésta, siguiendo a Ulloa, como "la coartación -el freno- del fin último, fin de descarga, de la pulsión (...) Esta coartación del impulso de apoderamiento del hijo, este límite a la descarga no ajeno a la ética" (Ulloa, 1995:135).

Es renunciando, entonces, al apoderamiento del infantil sujeto (Ulloa, 1995) que Otro puede sostener "la empatía, que garantizará el suministro adecuado (calor, alimento, arrullo, palabra) y como segundo y fundamental componente: el miramiento. Tener miramiento es mirar con amoroso interés a quien se reconoce como sujeto ajeno y distinto a uno mismo. El miramiento es germen inicial y garantía de autonomía futura del infante" (Ulloa, 1995:136).

Sostener esta posición en el lazo, soportar ser el Otro para otro es ser, a nuestro modo de entender, adulto. Es la figura de un adulto la que habilita el despliegue de un niño, niña o adolescente. Un adulto ya ha pasado por los avatares de la constitución subjetiva y por lo tanto ya ha perdido algo para ganarlo en otro nivel (Mannoni, 1983), ya ha capitalizado el No todo es posible y es esa la ganancia que se habilita a transmitir a la siguiente generación, porque es el lazo lo que se transmite y es la interpretación de él lo que hace a un sujeto (Kreszes, 2005).

Entonces, si consideramos la relación de asimetría con otro, la empatía y miramiento y la transmisión de límites como tres enlaces discursivos de la función institucional de filiación, podemos pensar que dados ellos tres, un alojamiento para niñas, niños y adolescentes es posible. Mejor dicho, alojar implica necesariamente sostener una relación asimétrica con el niño, niña o adolescente, mantener cierta empatía y miramiento y habilitarse como transmisor de límites. Es a través de ellos que un ordenamiento de las posiciones en el lazo es posible.

Para poder desarrollar escenas institucionales que nos permitan leer las posiciones en el lazo con otros, poniendo a jugar los tres ejes discursivos desarrollados previamente, utilizaremos la categoría ceremonias mínimas de Mercedes Minnicelli. Las ceremonias mínimas pueden pensarse como actos pequeños que se repiten en la cotidianidad mediante dichos o hechos. Caracterizarlas como unidad de análisis implica de una escucha activa que pueda recortarlas y analizarlas para hacer de lo dicho otros decires (Minnicelli, 2013). En ese sentido, según la autora, podemos, 
Otorgarles carácter de invención, de creadores de condiciones de posibilidad subjetivantes, que implica necesariamente entender que el poder (hacer) no se aloja en las grandes estructuras de manera exclusiva, sino que se sostiene en detalles mínimos, en la palabra, en el decir diario, en la posición de cada sujeto en lazo con otros. (Minnicelli, 2013:55)

Como instancias de intervención, las ceremonias mínimas "implican un reposicionamiento subjetivo de los adultos ante los niños, niñas y adolescentes" (Minnicelli, 2013: 55), permitiendo así: instituir otro discurso, desarticular discursos encriptados o analizar discursos y prácticas.

Por último, según Minnicelli, para que un acto tenga el carácter de ceremonia mínima debe contar con:

- El despliegue de una escena cuyo guión variará según la institución y el para qué de la misma.

- Personajes que juegan distintos roles, algunos protagonistas de la escena misma, otros creados ad hoc.

- Un marco témporo-espacial que no necesariamente queda establecido por el reloj, sino con un cada vez que..., antes de...o después de...Toda forma ceremonial presenta una reiteración y un momento de apertura, despliegue y cierre, generando muchas veces una suspensión del tiempo.

- Un marco simbólico que permita leer la transferencia desplegada.

Las primeras tres ceremonias mínimas descriptas intentan instituir otro discurso a lo dicho, mientras que las últimas dos son material de análisis de discursos y prácticas. La elección de estas ceremonias mínimas y no de otras está en relación a la repetición. Es la pregunta por esa repetición la que nos lleva a desglosarlas, encontrándonos en el recorrido con el lazo y las posiciones en él.

\section{Ceremonias Mínimas (instituir otro discurso)}

"Ustedes no son nadie en mi vida para decirme lo que tengo que hacer".

La escena tiene como protagonistas a una de las niñas alojadas en la institución, de seis años, y al Acompañante Convivencial (AC) que estaba a cargo de ella en ese momento. La niña, cada vez que tomaba un té intentaba ponerle diez cucharadas de azúcar. El AC quería explicarle lo mal que eso hacía y enseñarle otra forma. Ella devolvía: "Ustedes no son nadie en mi vida para decirme lo que tengo que hacer". Cada vez que desayunaba y cada vez. que merendaba, aparecía la regulación del AC y este dicho como respuesta.

La niña estaba siendo alojada en una nueva institución tanto para ella como para los trabajadores y para el Sistema de Protección Integral. Por lo tanto, se trataba de nuevas personas responsables de su cuidado que portaban modos de acercamiento y tratos distintos a los que la niña estaba acostumbrada. En la vieja institución, el té ya venía servido con el azúcar.

Pensar en el marco simbólico nos habilita a preguntarnos por la relación entra la niña y las personas que intentaban constituirse como adultos para con ella. El No frente a las diez cucharadas de azúcar era un pequeño acto que buscaba establecer una regulación frente al exceso. Ante esto aparece una respuesta que despliega la pregunta por el lazo con el otro.

Frente a la afirmación de la niña "ustedes no son nadie" nos preguntamos ¿quién era alguien para ella? ¿Ante qué sí quedaría subsumida? ¿Dónde se ubicaban las personas del cotidiano en el lazo con esta niña? Había, pues, alguien absoluto y había otro que tal vez tenía 
que prestarse al agujeramiento para hacerse un lugar en el lazo. La respuesta de los adultos fue: "Somos quienes, en este momento, te cuidamos y porque sos chiquita y nosotros somos grandes vamos a intentar enseñarte algunas cosas".

Con la sanción de la diferencia es que los adultos se habilitaron un lugar posible de transmisión en el cual algo se pierde y algo también se espera. Es desde esta nueva simbolización, que se puede admitir, al decir de Minnicelli,

una legalidad ordenadora que lleve a que $(. .$.$) otro intervenga delimitando$ hasta dónde se puede llegar mediante una acción determinada. Esto supone que quien interviene porte en sí una legalidad a la cual representa sin serlo. Allí mismo se crean, mediante el límite, posibilidades de otra cosa, otro espacio transicional (Minnicelli, 2004:15).

Sin los límites, como dice Paulo Freire en su obra Pedagogía de la Autonomía, "la libertad degenera en libertinaje y la autoridad en autoritarismo" (Freire, 2008: 99). Es interesante pensar la relación que el autor establece entre la libertad y la autoridad para sí después problematizar sobre la autonomía de los sujetos. "Lo que siempre busqué fue vivir en plenitud la relación tensa, contradictoria y no mecánica, entre autoridad y libertad, en el sentido de asegurar el respeto entre ambas, cuya ruptura provoca la hipertrofia de una o de otra". (Freire, 2008:102)

Sostener esta legalidad ordenadora implicaba, necesariamente, un posicionamiento subjetivo de los adultos ante la niña. Un posicionamiento ético tierno, retomando las conceptualizaciones de Fernando Ulloa (1995). Es desde esta ternura que sentían la suficiente empatía hacia ella como para criarla y el suficiente miramiento como para esperar amoro- samente que sus propios tiempos de tramitación trabajasen.

Según Freire, el desafío para los educadores democráticos, y podríamos agregar: también para los adultos que ofician de soportes de crianza de niños, niñas y adolescentes, es pensar "cómo trabajar para hacer posible que la necesidad del límite sea asumida en forma ética por la libertad. Cuanto más críticamente la libertad asuma el límite necesario, tanto más autoridad tendrá, desde el punto de vista de la ética, para seguir luchando en su nombre" (Freire, 2008: 100).

Los niños tienen derecho a una relación asimétrica, es necesario y fundante que haya un Otro que vaya demarcando el camino sin caer por eso en omnipotencias ni autoritarismos. Como dice Perla Zelmanovich,

no olvidar que hablar de niño significa pensar en una subjetividad en vías de constitución, que no está dada desde el vamos. Significa pensar en una subjetividad que se constituye en el discurso de los adultos, que requiere de alguien que le acerque al niño la lengua y la cultura, y que, al mismo tiempo, le ofrezca espacios de protección que le posibiliten aprehenderla. (Zelmanovich, 2003:3)

El desafío, entonces, es asumirse como pasadores de cultura (Lampugnani, 2014) de esta niña en ese momento y correrse, de esta manera, de la trampa que el discurso jurídico, con la fuerza de su arraigo en el sentido común de la sociedad, nos presenta: no necesariamente sólo la procreación y los lazos sanguíneos filian.

\section{"¿Qué hicieron mientras yo no estuve?"}

La pregunta es repetida por una niña de seis años cada vez que regresaba a la institución luego de alguna actividad. Era dirigida 
hacia las personas del lugar y aparecía cuando el resto de las residentes, o la gran mayoría, se habían quedado en la institución y ella había salido. En un principio, la niña pedía ir a lugares cercanos. Con el tiempo, fue eligiendo espacios un poco más alejados de la institución.

Se trataba de un primer momento de conocimiento y acercamiento entre la niña y el espacio: nueva institución para ella (y para el equipo de trabajo), nuevas personas como referencia, nuevo barrio, nuevo espacio de educación formal. Si bien el grupo de residentes era conocido, ya que convivía con ella desde sus tres años, el marco de esa convivencia era distinto.

Su pregunta fue escuchada por primera vez y respondida con extrañeza. La insistencia de ella fue transformando la extrañeza en curiosidad, la curiosidad en interrogante y el interrogante en una posible lectura.

Hay en este dicho una incógnita sobre su ausencia en el lugar que comenzaba a constituirse como referencia, una pregunta que habilita el despliegue de la operación psíquica presencia - ausencia fundante en la constitución del sujeto. A partir de una lectura de esta operación se intentó generar una nueva red discursiva en la escena institucional. El descubrimiento freudiano sobre el juego del Fort-Da pudo abonar la lectura.

En su obra Más allá del principio de placer, Freud describe la escena lúdica que un niño de un año y medio repite frente a la ausencia considerada de su madre: hace desaparecer y aparecer un carretel de madera atado con un piolín tras la baranda de su cuna (Freud, 2001). Esta observación, mucho más detallada en su obra, explicita la función que el juego de presencia - ausencia tiene para la constitución subjetiva. El niño hace aparecer y desaparecer los juguetes para, en un segundo momento, jugar él mismo a aparecer y desaparecer ante la mirada de su madre; y en ese movimiento transmuta la pasividad de la vida real a la acti- vidad de lo lúdico. Es él quien se va y vuelve para la madre, no al revés. La operación evidencia la construcción del lazo filiatorio con el Otro, en tanto se pueda faltarle al Otro y este Otro pueda soportarlo.

En el lazo, recordemos, el sujeto es llamado - por el Otro- a responder. Es desde un significante de la alteridad que es convocado, el significante "Tú". Ahora bien, ese "Tú" explicita, nuevamente, lo paradojal del lazo ya que, por un lado, es falo como deseo de la madre, por lo tanto anudado al deseo del Otro; y por el otro lado es el objeto a, como medida inconmensurable que imposibilita la identificación al falo (Kreszes, 2005).

La separación logra simbolizarse tolerando, entonces, esta paradoja (Rodulfo, 2010) y la búsqueda incesante del deseo se pone a andar. Se trata de un corte que como tal no es mera traducción sino, más bien, interpretación.

Resulta interesante retomar la experiencia institucional que llevó adelante Maud Mannoni en Bonneuil, Francia donde la relación de presencia - ausencia ante el Otro, representado por la propia institución, ha tenido un papel fundamental en la donación de un lugar para vivir para el niño sujeto enfermo (Mannoni, 1983) que llegaba a ser alojado. En la obra que recolecta la experiencia Un lugarpara vivir, Robert Lefort, compañero de Mannoni, cuestiona la omnipotencia que en la práctica las instituciones encarnan al comportarse como las madres de los psicóticos, dejando a los sujetos capturados por ella sin poder apartarse. "Una institución que pretenda ser distinta es la que, para producir un cierto contrapeso, asume el estallido y permite al sujeto situarse al nivel de la palabra, con posibilidad de separarse, de apartarse de la institución. Sin que por este motivo la institución se tambalee o le pida cuentas" (Lefort, 1983:52).

Desde el marco simbólico de esta ceremonia mínima podemos decir que es sosteniendo 
su ausencia como la niña de nuestra escena, de a poquito, va tolerando no estar. Es contándole qué fue lo que se hizo mientras ella no estuvo, guardándole un pedazo de la torta cocinada por la tarde, preguntándole qué hizo ella, despidiéndola con un "te esperamos para merendar juntas", que la niña fue y vino, emergiendo así un sujeto en busca de su deseo.

En su pregunta, además, se pudo escuchar cierto temor a lo que puede suceder con ese lugar mientras ella no esté: ¿estará al volver? Por esta razón, en ocasiones, los nuevos decires se acompañaban de objetos que hacían de representantes de un espacio en el otro y viceversa, en el intento de reafirmar la existencia de un lugar que la esperaba, la imaginaba, la proyectaba, por ejemplo, pedirle que a la vuelta de su salida traiga, junto al adulto con quien había salido, el dulce de leche para la torta o dejarle en la mochila escolar una cartita secreta para que encuentre una vez allá. Es ofertándole seguridad y confianza que la niña pudo separarse. Como dice Winnicott, "cuando hay fe y confiabilidad existe un espacio potencial, que puede convertirse en una zona infinita de separación, que el bebé, el niño, el adolescente, el adulto pueden llenar de juego en forma creadora" (Winnicott, 1982:144).

Ahora bien, ella decía "mientras yo no estuve", y con la apoyatura en las teorizaciones de Donald Winnicott preguntándose dónde estamos mientras vivimos, vale la pregunta ¿en dónde estuvo? Hay una zona intermedia, según el autor, en donde el juego como accionar creativo da lugar a la experiencia cultural. Es en este pasaje por distintos lugares que la niña abonó a su experiencia cultural y pudo hacerlo porque supo construir un lugar adonde poner lo que encontraba para poder buscar ser original dentro de la tradición. (Winnicott, 1982)

La nave que te lleva al mar...

"Buscame vos el viernes por la escuela, que quiero decirte algo". Con ese pedido de una niña de nueve años, la misma niña que protagonizó la primera ceremonia mínima descripta, uno de los AC se retiró de la institución un miércoles, sabiendo que el viernes iba a ser la última vez que busque a la niña por la escuela. El matrimonio adoptante con quienes hacía unos meses se estaban conociendo también iba a estar presente para entregar los últimos papeles, ya que a partir de ese día la niña comenzaría a vivir con ellos.

Luego de saludarse con las señoritas y con la consigna propuesta por ella de no hacer "despedida" con sus compañeros porque va a volver a saludarlos de vez en cuando, se dirigieron todos al auto del matrimonio para pasar por la institución y buscar sus cosas.

Es ahí cuando la niña agarró de la mano al Acompañante, adelantaron un par de pasos del resto y le anticipó:

"Ahora nos vamos a subir a mi auto, cuando nos subamos se va a transformar en una nave espacial. ¿Y sabes a dónde nos va a llevar?...nos va a llevar al mar; que es un lugar que a vos te gusta mucho y a mi también me gusta mucho, y siempre nos va a gustar..."

Son reiteradas las ocasiones en que el AC, el adulto de la escena, contaba a la niña historias sobre el mar, a veces para acompañarla a dormir y donarle la protección necesaria para lograr descansar; otras, mientras compartían el almuerzo intentando libidinizar el momento; algunas otras, para desmontar escenas de enojo permitiéndole salirse de ese lugar. Las historias sobre el mar aparecían como herramientas que permitían condiciones de posibilidad subjetivantes. Es interesante ubicar lo rico y valioso del cotidiano, del sostén de todos los días como el escenario posible para la construcción subjetiva de esta niña y de todos los niños, niñas y adolescentes.

Además, las historias sobre el mar sirvieron como elemento lúdico que apostaba a la creatividad del sujeto guiado por la premisa 
de brindar condiciones para que esta niña encuentrase un lugar en el lazo con el otro.

Tal vez algo de eso puede leerse en su dicho ante el adulto, en esa especie de despedida que sí planificó para él. Las historias sobre el mar parecían ser donaciones del Otro que la niña tomó para inventar-se la de ella misma. Armó su propia historia de viaje, de despedida, de destierro, navegando en un mar en búsqueda tal vez de nuevas identificaciones a las que anudarse; pero con la ganancia y el reconocimiento de una posición subjetiva en el lazo con el otro. Es desde ahí que encontrará las herramientas para responderles a los Otros con los que se enlace.

Vale recordar que estamos hablando de la misma niña que a sus seis años le decía a este Acompañante Convivencial y al resto de los integrantes del equipo que ellos no eran nadie en su vida para decirle lo que tenía que hacer. Entre el no ser nadie para ella y el mar que siempre les va a gustar a los dos hay una institucionalización del lazo filiatorio.

En la institución, mientras tanto, las bolsas del negocio Escape (local de ropa que a la niña tanto le gustaba), rebalsadas con sus cosas, esperaban subirse a la nave espacial. Los dibujos, los lápices de colores recontra usados y las pinturas de uñas viejas se daban pelea por caerse de las bolsas, mientras ella, junto a sus hermanas los levantaban eufóricamente para llevarlos a la nave. El bolso pesado lo llevaba el hombre; la mochila de la escuela, la mujer. La hermana mayor se acerca a la mujer para pedirle los datos de la nueva casa de su hermanita. La mujer se los da y les dice que a la noche los va a encontrar siempre.

El Acompañante de la escena pidió hablar a solas con la niña. El también tenía algo para decirle. Se retiraron a la habitación de ella. Una vez ahí, la niña buscaba no mirarlo, intentaba disimular sus nervios, abría y cerraba la puerta de la mesita de luz buscando más cosas por llevarse o por dejar. El acompañante adulto le dijo: "jSos irremplazable!". Se quedó quieta, levantó la mirada. "¿Sabes lo que quiere decir eso?". Silencio. Contesta: "Que nadie va a ocupar mi lugar, ¿no?" "Si, eso: que nadie va a ocupar tu lugar". Pareciera que el adulto tuvo la necesidad de reforzar junto a la niña el lugar ganado y desde ahí donarle la confianza y seguridad para continuar como plantea Winnicott (1982).

Vale la pregunta sobre si estaban dadas las condiciones para que la niña vaya a vivir con un matrimonio adoptante en el intento de constituirse como familia, más aún nos preguntamos: ¿siempre tiene que llegar ese momento en la vida de niños y niñas que viven en instituciones de alojamiento? ¿Vivir en familia implica, como por añadidura, filiación? Lo desarrollado en este artículo nos indica que no son las superestructuras solas las que filian, como familia o instituciones de alojamiento. Lo que filia es el despliegue de ciertas funciones que habilitan la emergencia del sujeto. Funciones que pueden ponerse a jugar tanto dentro de una familia como de una institución de alojamiento, depende, claramente, si hay adulto o no.

Vuelve la interpelación una vez más a los adultos que trabajamos intentando instituir infancia: ¿Qué representaciones manejamos sobre familia, sobre alojar? Es desandando esas propias representaciones que los niños, niñas y adolescentes como sujetos podrán forjar las propias y ver si quieren viajar al mar o no.

\section{Ceremonias Mínimas (análisis de discursos y prácticas)}

"Me falta la tarjeta de cole". "No encuentro unas medias". "Me sacaron otra vez los auriculares". "Hagan algo". "Ustedes no hacen nada".

Los dichos se repetían una y otra vez en el despliegue de una escena que tenía como pro- 
tagonistas las residentes de la institución y a las personas a cargo. Cada vez que faltaban algunas de sus pertenencias convocaban a ellas a hacer algo. Ante las respuestas de éstas, las residentes sancionaban: "Ustedes no hacen nada".

Es interesante resaltar que, para ese momento, la conformación de los grupos de la institución, el de las residentes y el del equipo de trabajo, se había modificado; implicando la ida y la llegada de nuevas residentes y nuevos trabajadores. En cuanto al equipo de trabajo, el cambio más movilizante estuvo relacionado con la modificación de la dirección de la institución ya que generó una transformación en los modos de dar tratamiento a los conflictos institucionales. Ahora bien, si consideramos la siguiente ceremonia mínima como un analizador de discursos y prácticas, es fundamental preguntarnos por la metabolización de estas transformaciones.

Los dichos citados se situaban, justamente, a partir de estos cambios; sobre todo la interpelación directa al adulto en cuanto a su hacer. Anteriormente eran aisladas las situaciones donde faltaba alguna pertenencia de las residentes; en esos casos, se realizaba una asamblea entre los presentes en donde la niña o joven afectada relataba lo que le estaba faltando, dónde lo había dejado por última vez y por qué era necesario y valioso para ella. En el transcurso del día el objeto perdido aparecía sin que nadie enunciase haberlo tenido.

La modificación en la lógica de trabajo se inauguró y escenificó con el modo de ingreso de una joven que, además, era totalmente desconocida para el resto de las residentes y para los adultos. Los dos ingresos anteriores se intentaron trabajar paulatinamente tanto con las protagonistas como con las residentes $y$, en ambos casos, se trataba de hermanas de antiguas residentes de la institución; fueron ellas, incluso, quienes pidieron convivir con sus hermanas. Asimismo, todas se conocían por su larga estadía en conjunto en una institución anterior ${ }^{3}$.

La llegada de esta nueva joven, en cambio, fue abrupta, sin un trabajo previo tanto para con ella como para el resto de las jóvenes. Llegó con lo puesto, sin ninguna documentación propia, ni ningún documento que indique la toma de la Medida de Protección Excepcional'; sólo un llamado telefónico de la directora del organismo estatal de ese momento, obligando a alojarla y una dirección dividida ante el pedido: una parte intentando conservar los viejos modos y otras, realizando lo ordenado. En el medio, el equipo de AC que comenzaba a vivenciar como otras lógicas de trabajo sobre los modos de alojar ingresaba al cotidiano de la institución. En un principio, esto generó enojo y frustración. La llegada de esta joven se vivenció como una violación y amenaza a lo construido, generando una reacción un tanto hostil y discriminativa por parte de todos los actores institucionales. Como dice Derrida en su obra La hospitalidad,

\footnotetext{
${ }^{3}$ Vale aclarar que en los cimientos de esta nueva institución de alojamiento, año 2012, se encontraba el objetivo de alojar a un grupo determinado de niñas y adolescentes que habían quedado sin lugar para ser alojadas luego de la intervención y cierre de la institución donde vivían. Fue el estado provincial quien dispuso de esos accionares debido a las denuncias sobre sus lógicas de trabajo y las prácticas totalizantes que se ejercían sobre los niños, niñas y adolescentes alojados ahí.

${ }^{4}$ Las medidas de protección excepcional son aquellas medidas subsidiarias y temporales que importan la privación de la niña, niño o adolescente del medio familiar o de su centro de vida en el que se encuentra cuando el interés superior de éstos así lo requiera. Tienen como objetivo la conservación o recuperación por parte del sujeto del pleno ejercicio y goce de sus derechos vulnerados y la reparación de sus consecuencias y sólo proceden cuando la aplicación de las medidas de protección integral resulten insuficientes $\mathrm{o}$ inadecuadas para su situación particular. (Ley Provincial $\mathrm{N}^{\circ} 12.967$ )
} 
En todas partes donde el "propio-hogar" es violado, en todas partes donde una violación en todo caso es sentida como tal, se puede prever una reacción privatizante, incluso familiarista, incluso, ampliando el círculo, etnocéntrica y nacionalista, y por lo tanto virtualmente xenófoba: no ya dirigida contra el extranjero como tal, sino, paradójicamente, contra la potencia técnica anónima (extranjera a la lengua o a la religión, tanto como a la familia y a la nación) que amenaza, con el "propiohogar", las condiciones tradicionales de la hospitalidad. (Derrida, 2014:57)

Esto nos permitió repensar los fundamentos iniciales de la práctica y lo poco analizados que fueron en su momento: en el anhelo de construir un lugar para vivir (Mannoni, 1983) para estas niñas y adolescentes en particular, se construyó un propio-hogar que, por su propia definición, se volvió hostil a todo lo de afuera. ¿Cuánto de esta construcción habilitó el despliegue de condiciones de posibilidad subjetivantes (Minnicelli, 2013) y cuánto negó el contexto de la experiencia?

Volviendo a la escena, el marco simbólico habla de un nuevo equipo de trabajo que debía, por un lado y frente a la imposibilidad de alcanzar los objetivos estipulados al comienzo, repensar la lógica de trabajo y, por el otro, construir referencialidad ante las nuevas jóvenes. El llamado incesante de las mismas los convocaba a hacer ¿qué? El accionar asambleario que se llevaba adelante previamente ante estas situaciones también había quedado cristalizado. Al preguntarles qué esperaban que hicieran, las jóvenes contestaban: "que nos revisen, cómo se hacía en el otro lugar” (en referencia a la residencia previa). La negación a esta propuesta era rotunda, pero a cambio ¿qué ofertar? Resulta interesante pensar que no eran sólo las jóvenes quienes se sentían despojadas de sus cosas y por lo tanto de su lugar. El equipo de trabajo de AC vivenciaba el mismo despojo en relación a los modos de dar tratamiento dejándolos, aparentemente, sin herramientas para trabajar.

¿Cómo salirse, entonces, de esa encerrona? En la apelación a otro, a un tercero mediador, siguiendo a Ulloa, el equipo pudo empezar a "componer una narración" (Ulloa, 1995:195). En espacios de retrabajo con alguien externo de la institución se pudieron desplegar interrogantes taponados por la dinámica de la encerrona, preguntándose por la propia posición ante este panorama y renovando las herramientas útiles para hacer otros decires de lo dicho. ¿Cómo recuperar el sentido de pertenencia con la institución y desde ahí convocar a las jóvenes?

Los aportes de Minnicelli en Ceremonias Minimas sobre los sentidos del término pertenencia, permiten hacer una grieta en esta escena institucional tan encriptada. La autora desarrolla, por un lado, la pertenencia desde el sentido de la propiedad, pero, también, la pertenencia desde el sentirse parte. Dice,

pertenencia tiene también otro sentido que nos interesa destacar, y es el valor de sentirse parte, incluido, perteneciente a...Algo de lo propio se encuentra en ciertos lugares que nos hace sentirnos que somos parte, que nos identificamos, en definitiva, que no es indistinto para nosotros ni para los otros estar o no estar allí, porque nos sentimos reconocidos. (Minnicelli, 2013: 94)

Si los AC pudiesen construir algo de lo propio en los nuevos modos de dar tratamiento podrían darles lugar a ellas también, hacerlas parte, reconocerlas en la diferencia e instalarla en un sentido simbólico; porque, como plan- 
tea Minnicelli, si a los niños y jóvenes

no los albergamos, si no les trasmitimos ciertas llaves y claves para tolerar el malestar propio a la presencia de los otros, en la intemperie, ellos mismos crean sus propias claves; como bien nos lo enseñan los grupos de chicos a la intemperie de la vida, agrupados en bandas que los hacen sentirse parte de algún lugar en el mundo, por la vía de la crueldad sin límites. (Minnicelli, 2013:95)

Entonces, al quedar encandilados con la caída de aquel brillante ideal del inicio de la experiencia y sintiéndose impotentes, las jóvenes remitían a otros modos ya conocidos. El "No hacen nada" los obligó a despertarse, asumir la responsabilidad que tenían como adultos ante las jóvenes, reencontrar su propio sentido de pertenencia institucional y, desde ahí, volver a invitarlas a ser parte del lugar.

"Bueno, ¿qué quieren? Somos adolescentes".

Es esta la respuesta que daban las jóvenes cada vez que se les hacía una observación sobre su comportamiento en la cotidianidad de la institución. Era con enojo que lo transmitían y con estupor lo escuchaban los AC. Las observaciones se daban cuando no se cumplía con lo acordado, por ejemplo: levantarse para ir a la escuela, respetar el horario de vuelta de las salidas, colaborar con la limpieza de sus habitaciones.

En ese momento, tal como en la ceremonia mínima anterior, había habido cambios en el grupo de residentes, sólo quedaban jóvenes entre catorce y diecinueve años y también nuevos integrantes en la dirección de la institución.

La ida de la última niña alojada motivó a la nueva dirección a proponer acciones que, según su lectura, se condicionaban con la función de alojar adolescentes, por ejemplo, con- vocar a las jóvenes a sacar los juguetes que quedaban en la casa, flexibilizar los horarios establecidos que supieron demarcar hábitos y rituales en la institución, como los horarios para comer, dejar de convocarlas en el sostén cotidiano de la casa, como cocinar junto a ellas, hacer las compras u ordenar. Vale recordar que desde el comienzo de la experiencia se intentó trabajar con las residentes jóvenes la construcción de herramientas para poder llevar adelante proyectos autónomos propios; para esto, y a modo de ensayo, se las hacía partícipe, no sin dificultades, de las tareas hogareñas, como armar los menúes semanales, realizar las compras, administrar el dinero destinado para eso y organizar la limpieza. En este momento, los AC llevaban adelante esta tarea solos. Además, las jóvenes se levantaban a la hora que podían/querían y comían lo que cada una quería a cualquier hora.

Para preguntarnos por los dichos de las jóvenes es pertinente interrogar primero los propios haceres y dichos de los adultos referentes que dejaban entrever la construcción que portaban sobre la adolescencia; y así problematizar el marco simbólico de la escena institucional; porque ahí donde esperemos a un niño o adolescente, ahí mismo va a llegar.

Los dichos de las jóvenes devolvían en espejo el lugar donde eran colocadas, desresponsabilizandolas de sus acciones porque, total, son adolescentes. Si recordamos lo paradojal del lazo filiatorio en la ligadura y desligadura, podemos pensar que desresponsabilizar implica necesariamente no dar lugar a la respuesta del otro, por lo tanto no dar lugar al sujeto, entendiendo que "responsabilidad es un término que proviene del latín, responderé, y su connotación es justamente la de dar respuesta" (Flesler, 2014:8).

Podemos pensar que si no se espera una respuesta es porque no hay una visión de la alteridad presente, sosteniendo sólo lo pro- 
puesto y evitando así la invención creativa del sujeto ya que, siguiendo a Fresler, "en la respuesta, llave para abrirse paso a la libertad, el sujeto va insertando un rasgo distintivo, no idéntico al niño que le fue propuesto ser. Contribuye de ese modo a plasmar para sí un marco de existencia, más allá del espacio que lo vio nacer" (Fresler, 2011:64).

Es sumamente interesante la distinción que la autora hace entre las operaciones responder y realizar abriendo la dimensión temporal entre ellas, planteando que

No es lo mismo responder como sujeto al Otro que realizar la presencia del objeto en el fantasma del Otro (...) entre las dos opciones, se define una magna diferencia estructural para el sujeto. En términos más bien de orden lógico, entre uno y otro se va abriendo paso el no todo que enlaza la vida del sujeto a la incompletud de la existencia. (Fresler, 2011: 67)

Pareciera que ante el significante adolescente que a las jóvenes les llegaba desde el campo del Otro sin intervalo, sólo les quedaba realizar la presencia del objeto cuando "falla la falta" (Fresler, 2011:67).

Igualmente, con la interpelación directa hacia los adultos "iqué quieren?", las jóvenes evidenciaban lo contradictorio de su discurso: se les pedía que actuasen de una manera cuando sus acciones no abonaban a que pudiesen hacerlo. Se les pedía que respetaran los marcos cuando eran ellos los primeros en desarmarlos o ignorarlos. ¿Qué le suponía ese equipo a la adolescencia? ¿Qué se esperaba de ella? Y aún más: ¿se han preguntado por la adolescencia, por estas adolescencias, o simplemente se trabajaba con los preconceptos que cada uno de los integrantes contaba desde su propia experiencia personal o profesional?

No hay registros de ese trabajo al interior del equipo; sólo pasado un tiempo, con un nuevo cambio en la conformación del mismo y ante la inminente realidad de transformarse en una institución de alojamiento para adolescentes, es que estos interrogantes aparecen en el intento de llenar de sentido la frase alojar adolescentes.

Es interesante problematizar sobre las condiciones que caracterizarían el concepto adolescencia: ¿Es una cuestión de edad? ¿Se trata de una actitud? ¿Puede pensarse como un tiempo de tránsito entre la infancia y la adultez? Tal vez podamos pensarlo como un proceso más en la intrincada constitución subjetiva, estando advertidos que, siguiendo a Marisa Rodulfo,

estos procesos no están referidos meramente a estadios en un desarrollo lineal. Si bien tienen un irreductible despliegue en el eje diacrónico de la estructura, quedan incorporados como un funcionamiento permanente, "capas de lava" como decía Freud para pensar la simultaneidad; en razón de ello, estas vicisitudes, se reencuentran en un paciente de cualquier edad. (Rodulfo, 2010: 32)

Según Arminda Aberastury, hay tres duelos fundamentales que el sujeto realiza en ese momento: el duelo por el cuerpo infantil perdido, el duelo por el rol y la identidad infantiles y el duelo por los padres de la infancia (Aberastury, 1976). Hay pérdidas, resignificaciones y búsquedas, lejos de "ser una etapa estabilizada es proceso y desarrollo" (Knobel, 1976:10) que no necesariamente implica sólo dolor, a pesar de que el término adolescer esté referido al sufrir y padecer. La visión del adolescente que adolece, que sufre, es una visión adultocéntrica que evidencia, siguiendo a 